\title{
Dimensionless numbers for the net present value and the perpetual value of sustainable timber harvests from a monospecific uneven-aged
}

\section{forest}

\author{
Ignacio López Torres ${ }^{(1)}$, \\ Carmen Fullana Belda ${ }^{(2)}$
}

\section{Introduction}

By applying conditions of stable equilib rium from a matrix model, a recent study (López \& Fullana 2015) found dimensionless numbers $\hat{\lambda}_{0}, \hat{s}$, and $\hat{s}^{\prime}$ to provide reliable approximations of, respectively, the population growth rate, $\lambda_{0}$, the "sustainable/stable" harvest rate, $s$, where (eqn. 1):

$$
s=\frac{\lambda_{0}-1}{\lambda_{0}}
$$

$\square$ (1) Universidad Politécnica de Madrid (UPM), Escuela Técnica Superior de Ingeniería de Montes, Forestal y del Medio Natural, Ciudad Universitaria, E-28040 Madrid (Spain); (2) Universidad Pontificia de Comillas, Alberto Aguilera 23, E-28015 Madrid (Spain)

@ Ignacio López Torres (i.lopez@upm.es)

Received: Dec 21, 2017 - Accepted: Oct 19, 2018

Citation: López Torres I, Fullana Belda C (2019). Dimensionless numbers for the net present value and the perpetual value of sustainable timber harvests from a monospecific uneven-aged forest. iForest 12: 35-42. - doi: 10.3832/ifor2715-011 [online 2019-01-10]

Communicated by: Tomás Vrska

This paper proposes a simple and direct method to provide reliable approximations of the net present value (NPV) and the perpetual value (PV) of sustain able timber harvests from a monospecific uneven-aged forest based on dimensionless numbers. In addition, two new dimensionless numbers $\rho_{\mathrm{NPV}}$ and $\rho_{\mathrm{PV}}$ are introduced. These use the NPV or PV derived from the sale of timber throughout a harvest cycle, plus the final stocking value (as numerator), and the fair value of standing timber under IAS 41 (as denominator). They can be interpreted as economic performance indicators for forest management, inspired by the return on assets accounting concept, showing how profitable the forest is, relative to its total value, with sustainability and stability criteria. Those approximations to the variables NPV, PV, $\rho_{\mathrm{NPV}}$ and $\rho_{\mathrm{PV}}$, were obtained under conditions of stable equilibrium from a matrix model. In order to exemplify and test the results, the model used data from uneven-aged managed Pinus nigra stands, considering three levels of tree diameter growth, six levels of basal area and 33 levels of recruitment, creating a total of 594 planning scenarios. Furthermore, the study revealed the existence of strong linear correlations between those variables and a dimensionless number.

Keywords: Dimensionless Numbers, NPV / PV, Equilibrium, Sustainable Harvesting, Matrix Model, IAS 41

and the proportion of trees that has to remain unharvested in order to retain the stable diameter distribution, $s^{\prime}$ (where $s^{\prime}=$ $\left.1 / \lambda_{0}=1-s\right)$, of a forest stand, by means of the following expressions (eqn. 2, eqn. 3, eqn. 4):

$$
\begin{aligned}
\hat{\lambda}_{0} & =1+\sqrt[n]{\frac{(2 n-1)^{2} \pi w^{2} R \prod_{i=1}^{n-1} p_{i}}{16 G}} \\
\hat{s} & =1-\left[1+\sqrt[n]{\left.\frac{(2 n-1)^{2} \pi w^{2} R \prod_{i-1}^{n-1} p_{i}}{16 G}\right]^{-1}}\right. \\
& =\frac{\hat{\lambda}_{0}-1}{\hat{\lambda}_{0}} \\
\hat{s} & =1-\hat{s}=\frac{1}{\hat{\lambda}_{0}}= \\
& =\left[1+n_{\frac{n}{(2 n-1)^{2} \pi w^{2} R \prod_{i=1}^{n-1} p_{1}}}^{16 G}\right]^{-1}
\end{aligned}
$$
involved in the problem at hand. Hence, their importance and wide use in many fields, such as mathematics, physics, biol-

(3) In financial sciences in general, indicators

where $R$ is the global amount of recruitment, $G$ the stand basal area, $p_{i}$ the transition probabilities between adjacent diameter classes, and $n$ and $w$, respectively, the number and width of the diameter classes, as detailed below (the use of the circumflex above a variable here denotes a new object that represents an approximation to that variable, as defined in eqn. 2 , eqn. 3 and eqn. 4).

Dimensionless numbers are numbers that ogy, engineering, and economics (Szirtes 2007). to quantify financial return have been widely applied, using the internal rate of return (IRR) and the return on assets (ROA Brealey et al. 2016). The IRR is defined as the discount rate that makes the net present value (NPV) equal to zero, and the ROA is expressed as the quotient between

represent a property of a system, but do area, mass or time, associated with them Where such numbers exist for a specific system, they allow conclusions about the behaviour of the system to be extracted, without the need for a more detailed forprofit and the sum of invested capital. Attempts to derive similar return indicators for forests are discussed in detail in Knoke (2017). Mills \& Hoover (1982) calculated the annual change in the market value of standing timber stock and land, divided by the market value of timber and land at the beginning of the year, to obtain an indicator for US timberland. Weber (2002) computed a similar index for German tree species in order to define an indicator for "forest performance", and Hyytiäinen \& Penttinen (2008) applied the same perspective in their analyses of forest assets in Finland. 
Tab. 1 - Transition probabilities between diameter classes for each quality. $(n)$ : number of diameter classes; $(w)$ : width of the diameter classes $(=6 \mathrm{~cm})$.

\begin{tabular}{cccc}
\hline \multirow{2}{*}{$n$} & Quality I & Quality II & Quality III \\
\cline { 2 - 4 } & $\mathbf{9}$ & $\mathbf{8}$ & $\mathbf{7}$ \\
\hline$(0,6] \rightarrow(6,12]$ & $\mathrm{p}_{1}=0.7697$ & $\mathrm{p}_{1}=0.5951$ & $\mathrm{p}_{1}=0.4564$ \\
$(6,12] \rightarrow(12,18]$ & $\mathrm{p}_{2}=0.8602$ & $\mathrm{p}_{2}=0.6824$ & $\mathrm{p}_{2}=0.5326$ \\
\hline$(12,18] \rightarrow(18,24]$ & $\mathrm{p}_{3}=0.7913$ & $\mathrm{p}_{3}=0.6200$ & $\mathrm{p}_{3}=0.4697$ \\
$(18,24] \rightarrow(24,30]$ & $\mathrm{p}_{4}=0.6828$ & $\mathrm{p}_{4}=0.5190$ & $\mathrm{p}_{4}=0.3692$ \\
\hline$(24,30] \rightarrow(30,36]$ & $\mathrm{p}_{5}=0.5533$ & $\mathrm{p}_{5}=0.3971$ & $\mathrm{p}_{5}=0.2475$ \\
$(30,36] \rightarrow(36,42]$ & $\mathrm{p}_{6}=0.4106$ & $\mathrm{p}_{6}=0.2618$ & $\mathrm{p}_{6}=0.1119$ \\
$(36,42] \rightarrow(42,48]$ & $\mathrm{p}_{7}=0.2587$ & $\mathrm{p}_{7}=0.1171$ & - \\
$(42,48] \rightarrow(48, \rightarrow)$ & $\mathrm{p}_{8}=0.1000$ & - & - \\
\hline$\prod p_{\mathrm{k}}$ & 0.002104 & 0.001590 & 0.001168 \\
\hline
\end{tabular}

In this context, the main aim of this study was to investigate whether there were relationships between those dimensionless numbers (in particular, eqn. 3 ) and the NPV and PV of sustainable timber harvests from a monospecific uneven-aged forest. In addition, we have introduced two new dimensionless numbers, $\rho_{\mathrm{NPV}}$ and $\rho_{\mathrm{PV}}$, using the NPV or PV derived from the sale of timber throughout a harvest cycle, plus the final stocking value (as numerator), and the fair value of the standing timber under IAS 41 (IASB 2000) as denominator. These can be interpreted as economic performance indicators for forest management, inspired by the ROA accounting concept, showing how profitable the forest is, relative to its total value, with sustainability and stability criteria. Moreover, we demonstrated that there are strong linear correlations between those numbers and $\hat{s}$; to that end, it will be used the matrix model applied to uneven-aged managed Pinus nigra stands by López et al. (2012, 2013, 2016), which accurately describes the stand dynamics.

Matrix models, introduced by Leslie (1945) and modified by Lefkovitch (1965) by grouping organisms in terms of stage categories rather than age categories, have been applied to almost all the subject areas of forestry (Usher 1969, Caswell 2001, Vanclay 2012, Liang \& Picard 2013). In forest management, matrix models have been applied, for example, to evaluate economic outcomes (Buongiorno \& Michie 1980, Fortini et al. 2015) and ecological impacts (Van Mantgem \& Stephenson 2005, Zhou et al. 2008), or to optimise silviculture in mixed uneven-aged forests to increase the recruitment of browse-sensitive tree species without intervening in the ungulate population (Ficko et al. 2018). A matrix population model works in discrete time, projecting a population from time $t$ to $t+1$ using a transition matrix ( 1 here represents the time step or projection interval). It is defined by the finite difference linear system of equations $X(t+1)=A X(t)$, where $X(t)$ and $X(t+1)$ are column vectors containing the number of stems ha ${ }^{-1}$ within each diameter class at time $t$ and $t+1$, respectively, and $A$ is the transition matrix. In these models, the population growth rate (i.e., the temporal rate of exponential change of the population number of individuals in the long term) is the dominant eigenvalue, $\lambda_{0}$ of $A$, and the equilibrium position (stable diameter distribution in this study) is determined by the right eigenvector, $W_{0}$, corresponding to $\lambda_{0}$. By asymptotic analysis
Fig. 1 - Diameter growth models. I: site index $20, D=$ $51.68\left(1-\mathrm{e}^{-0.015259 t}\right)^{1.255111} ;$ II: site index $17, D=46.645633(1$ $\left.\mathrm{e}^{-0.014318 t}\right)^{1.337062}$; and III: site index $14, D=40.644134$ ( 1 $\left.\mathrm{e}^{-0.013838 \mathrm{t}}\right)^{1.456382} \cdot(D): \mathrm{dbh}$ in $\mathrm{cm}$; $(t)$ : time in years. The coefficient of determination was always greater than 0.999 .

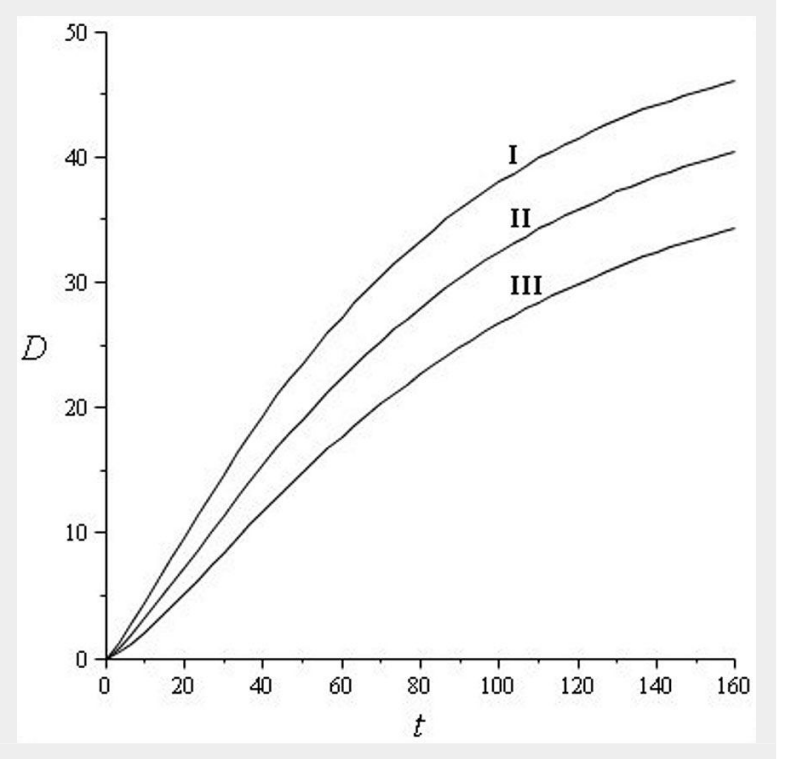

(long term behaviour), we know that, independent of the initial conditions, when $\lambda_{0}>$ 1 , the total number of stems ha-1 of the tree population increases exponentially over time (unless harvests are conducted); when $\lambda_{0}<1$ the population decays until extinction; and when $\lambda_{0}=1$, a stable distribution proportional to $W_{0}$ is obtained. Gotelli (2001) referred to the special case of the stable distribution when $\lambda_{0}=1$ as the "stationary distribution"; we considered the same case in reference to the stable diameter distribution of the stand $W_{0}$.

\section{Materials and methods}

\section{Stand population dynamics model}

The matrix model uses the transition probabilities obtained in López et al. (2012, 2013) for uneven-aged managed Pinus nigra stands, considering three levels of tree diameter growth (Quality I, faster; Quality II, medium; and Quality III, slower diameter growth - Tab. 1, Fig. 1). The stands are located in the Spanish Iberian System, a mountain range extending about $400 \mathrm{~km}$ along the north-eastern edge of the central plateau, concentrating $60 \%$ of the area occupied by Pinus nigra in Spain (Grande \& García Abril 2005). Based on data from those stands, the model simulates outcomes for 594 different forest management planning scenarios: three diameter growth levels (Qualities I-III) $\times$ six basal area levels $\left(G=21\right.$ to $\left.G=26 \mathrm{~m}^{2} \mathrm{ha}^{-1}\right) \times 33$ recruitment levels $(R=200$ to $R=840$ stems $\left.h^{-1}\right)$. Group selection cutting was the silvicultural system used because Pinus nigra is not a shade-tolerant species, and the gaps opened in the canopy through single-tree selection cutting would not be large enough to ensure regeneration.

Since the harvesting operations in the study area generally took place every 10 years, this was the time step adopted in the model. Considering this time step, trees were grouped into $n$ diameter classes of equal width, $w=6 \mathrm{~cm}:(0,6),(6,12),(12$, $18), \ldots,(30,36), \ldots$, with the last class being $(48, \rightarrow$; more than $48 \mathrm{~cm})$ for Quality I, $(42, \rightarrow$; more than $42 \mathrm{~cm})$ for Quality II and $(36, \rightarrow$; more than $36 \mathrm{~cm})$ for Quality III. Therefore, an individual tree in class $k$ could remain in class $k$ or progress to class $k+1$ during the projection interval $(t, t+1)$. The number of trees in each class changed in each projection interval, because some were harvested, some remained in the same diameter class and others grew past the boundary to the next diameter class. In such conditions, $p_{\mathrm{k}}$ is the probability that an individual tree in class $k$ at time $t$ (initial) will appear in class $k+1$ at time $t+1$ (final time of projection); the recruitment coefficient, $r_{k}$, is the number of offspring (stems $\left.\mathrm{ha}^{-1}\right)$ living at time $t+1$ produced in the interval of projection $(t, t+1)$ by an average tree in class $k$ at time $t$ (similar to many standard size classified matrix models, $r_{1}=0-$ Caswell 2001); $h_{k}(t)$ defines the proportion of harvested trees in class $k$, natural mor- 
tality included; $x_{k}(t)$ and $x_{k}(t+1)$ describe the stem densities in class $k$ at the initial and final times of projection. Finally, $R=r_{2}$ $x_{2}+r_{3} x_{3}+\ldots+r_{n} x_{n}$ denotes the global amount of recruitment at each time step, defined as the total number of trees entering into the first diameter class from $t$ to $t+1$, generally above a certain threshold diameter. Notice that $0<p_{k}<1$ for $k=1,2, \ldots$, $n-1 ; r_{k} \geq 0$ for $k=2,3, \ldots, n$, with $R=0$, if and only if $r_{k}=0$ for all $k$; and $x_{k}>0$ for $k=1,2$, $\ldots, n$.

By analysing the dynamics of the projections, we found that the model is described accurately by the matrix model (eqn. 5):

$$
X(t+1)=A[I-H(t)] X(t)
$$

where (eqn. 6):

$A=\left[\begin{array}{cccccc}1-p_{1} & r_{2} & r_{3} & \cdots & r_{n-1} & r_{n} \\ p_{1} & 1-p_{2} & 0 & \cdots & 0 & 0 \\ 0 & p_{2} & 1-p_{3} & \cdots & 0 & 0 \\ \vdots & \vdots & \vdots & \ddots & \vdots & \vdots \\ 0 & 0 & 0 & \cdots & 1-p_{n-1} & 0 \\ 0 & 0 & 0 & \cdots & p_{n-1} & 1\end{array}\right]$

$I$ is the identity matrix of order $n, H(t)=$ $\operatorname{diag}\left[h_{1}(t), h_{2}(t), \ldots, h_{n}(t)\right]$ is a diagonal matrix with the harvest rates $h_{k}(t)$, including natural mortalities, and $X(t)$ and $X(t+1)$ are column vectors indicating the stem densities at the initial and final times of projection, respectively.

\section{Sustainable/stable harvesting strategy} and stable diameter distribution

The "sustainable/stable" harvesting strategy is aimed at reaching the stable diameter distribution of the stand for each harvest, yielding the harvest rate, s, shown in eqn. 1 for all the diameter classes and time steps; the population growth rate, $\lambda_{0}$, is the dominant eigenvalue of the transition matrix without harvests (i.e., matrix $A$ ), and $s$ also includes the natural mortalities. This is a sustainable harvesting strategy too (in the sense of population persistence over time) because $s$ corresponds to the case in which the right eigenvector associated with the dominant eigenvalue equal to 1 of the transition matrix with harvests, i.e., matrix $A(I-H)$, is $W_{0}$.

On the other hand, the equilibrium is defined by the stable diameter distribution of the stand $W_{0}$, which is simultaneously the right eigenvector of the matrices $A$ and $A(I-$ $H$ ) corresponding, respectively, to the dominant eigenvalues $\lambda_{0}$ and 1 . Thus the components of the stable diameter distribution of the stand $N_{1}, N_{2}, \ldots, N_{n}$ (stems ha1) were obtained by solving the linear system $A W_{0}=\lambda_{0} W_{0}$, yielding (proportional to) the vector $W_{0}=\left(N_{1}, N_{2}, N_{3}, \ldots, N_{n-1}, N_{n}\right)$, where (eqn. 7):

$$
\begin{aligned}
& N_{i}=\left(\lambda_{0}-1\right) \prod_{k=2}^{n-1}\left(\lambda_{0}-1+p_{k}\right), \\
& N_{i}=\left(\lambda_{0}-1\right)\left(\prod_{k=1}^{i-1} p_{k}\right)\left(\prod_{k=i+1}^{n-1}\left(\lambda_{0}-1+p_{k}\right)\right)
\end{aligned}
$$

Tab. 2 - Stumpage prices $\left(€ \mathrm{~m}^{-3}\right)$ of Pinus nigra in Spain according to diameter class and industrial destination.

\begin{tabular}{lccc}
\hline \multirow{2}{*}{ Products } & \multicolumn{3}{c}{ Diameter classes $(\mathbf{c m})$} \\
\cline { 2 - 4 } & $<\mathbf{2 0}$ & $\mathbf{2 0 - 4 0}$ & $>\mathbf{4 0}$ \\
\hline Particle & 6 & 1.2 & 0.6 \\
Poles & 0 & 11.85 & 0 \\
\hline Sawlog & 0 & 9.8 & 11.76 \\
High-quality sawlog & 0 & 0 & 9.96 \\
\hline Total average price & 6 & 22.85 & 22.32 \\
\hline
\end{tabular}

for $1<i<n-1$, and (eqn. 8):

$$
\begin{aligned}
& N_{n-1}=\left(\lambda_{0}-1\right) \prod_{k=1}^{n-2} p_{k}, \\
& N_{n}=\prod_{k=1}^{n-1} p_{k}
\end{aligned}
$$

\section{NPV function}

Considering that the main aim for the stands in the study area is the production of timber, the objective function is the NPV of all management operations over a planning horizon of $T$ years, discounted to the beginning of the period, that is (eqn. 9):

$$
\begin{aligned}
N P V= & \sum_{k=1}^{n} \sum_{t=0}^{T-10} x_{k}(t) h_{k}(t) v_{k}(t) \frac{1}{(1+i)^{t}} \\
& +\sum_{k=1}^{N} x_{k}(T) v_{k}(T) \frac{1}{(1+i)^{T}}
\end{aligned}
$$

where $v_{k}(t)$ is the stumpage value that corresponds to class $k$ at year $t\left(\epsilon\right.$ stem $\left.^{-1}\right)$ and $i$ is the discount rate (López et al. 2013, 2016). The first summation represents the income derived from the sale of timber, and the second is the final stocking value. Harvesting costs are not considered because it is assumed that harvesting operations are not paid for the owner, but for the buyer of the stumpage. The costs for the owner of the land are the opportunity cost of invested capital and the opportunity cost of land. None of them are explicit costs, but they are incorporated into the NPV function. It is well known that the NPV is a justifiable management objective for a single economic goal (Siegel et al. 1995).

The corresponding function of that management regime maintained in perpetuity is given by (eqn. 10):

$$
P V=\sum_{k=1}^{n} \sum_{t=0}^{\infty} x_{k}(t) h_{k}(t) v_{k}(t) \frac{1}{(1+i)^{t}}
$$

In the case of the equilibrium defined by the "sustainable/stable" harvesting strategy, since $h_{k}(t)=s, x_{k}(t)=N_{k}$, for $k=1,2, \ldots$, $n$ and $t=0,10,20, \ldots$, the above equations become (eqn. 11, eqn. 12):

$$
\begin{aligned}
N P V & =\sum_{k=1}^{n} \sum_{t=0}^{T-10} N_{k} s v_{k}(t) \frac{1}{(1+i)^{t}} \\
& +\sum_{k=1}^{n} N_{k} v_{k}(t) \frac{1}{(1+i)^{T}} \\
P V & =\sum_{k=1}^{n} \sum_{t=0}^{\infty} N_{k} s v_{k}(t) \frac{1}{(1+i)^{t}}
\end{aligned}
$$

Since the stumpage prices of Pinus nigra (MAGRAMA 2012), simplifying eqn. 11 and eqn. 12 we obtain (eqn. 13, eqn. 14):

$$
\begin{aligned}
N P V & =s \sum_{k=1}^{n} N_{k} v_{k} \sum_{t=0}^{T-10} \frac{1}{(1+i)^{t}}+ \\
& +\sum_{k=1}^{n} N_{k} v_{k} \frac{1}{(1+i)^{T}}= \\
& =\left[s \frac{(1+i)^{-T}-1}{(1+i)^{-10}-1}+\frac{1}{(1+i)^{T}}\right] \sum_{k=1}^{n} N_{k} v_{k} \\
P V= & s \sum_{k=1}^{n} N_{k} v_{k} \sum_{t=0}^{\infty} \frac{1}{(1+i)^{t}}= \\
= & s \frac{1}{1-(1+i)^{-10}} \sum_{k=1}^{n} N_{k} v_{k}
\end{aligned}
$$

where $\sum N_{k} V_{k}$ represents the fair value of standing timber under IAS 41 (IASB 2000). By dividing eqn. 13 and eqn. 14 by this value, we obtain (eqn. 15, eqn. 16):

$$
\begin{aligned}
& \rho_{N P V}=\frac{N P V}{\sum_{k=1}^{n} N_{k} v_{k}}=s \frac{(1+i)^{-T}-1}{(1+i)^{-10}-1}+\frac{1}{(1+i)^{T}} \\
& \rho_{P V}=\frac{P V}{\sum_{k=1}^{n} N_{k} v_{k}}=s \frac{1}{1-(1+i)^{-10}}
\end{aligned}
$$

which means that, for previously defined values of $i$ and $T$, there is a positive linear correlation between the NPV weighted by the fair value of standing timber, $\sum N_{k} v_{k}$, that is $\rho_{\mathrm{NPV}}$, and $s$ (resp. between the PV weighted by $\sum N_{k} v_{k}$, that is $\rho_{\mathrm{Pv}}$, and $s$ ). Note that $\rho_{\mathrm{NPV}}$ and $\rho_{\mathrm{PV}}$ are dimensionless numbers. Furthermore, given that there is a strong positive linear correlation between $s$ and $\hat{s}$, (López \& Fullana 2015), it is expected that, for previously defined values of $i$ and $T$, there must be a strong positive linear correlation between these variables $\rho_{\mathrm{NPV}}$ and $\rho_{\mathrm{PV}}$, and $\hat{s}$, as we demonstrate below.

\section{Stumpage value model}

The stumpage value model applied in this study comes from López et al. (2013, 2016). In Tab. 2, we provide the stumpage values we used to obtain the economic data (Montero et al. 1992, Trasobares \& Pukkala 2004). The regression models adjusted to these data appear in Fig. 2. The stumpage prices of Pinus nigra in Spain remained fairly stable between 1994 and 2011 (MAGRAMA 2012). in Spain remain fairly stable through time 
Fig. 2 - Stumpage value models: Quality I: $v=D^{3.186471}$ $\exp (-7.704952-8.678687$. $\left.10^{-3} \mathrm{D}\right)$; Quality II: $v=D^{3.114196}$ $\exp (-7.476506-9.903125$. $\left.10^{-3} \mathrm{D}\right)$; and Quality III: $v=$ $D^{2.987053} \exp (-7.110977$ $\left.1.078752 \cdot 10^{-2} \mathrm{D}\right)$; stumpage values $(v)$ in $€$ stem $^{-1}$ and diameter $(D)$ in $\mathrm{cm}$. The coefficient of determination was always greater than 0.9999 .

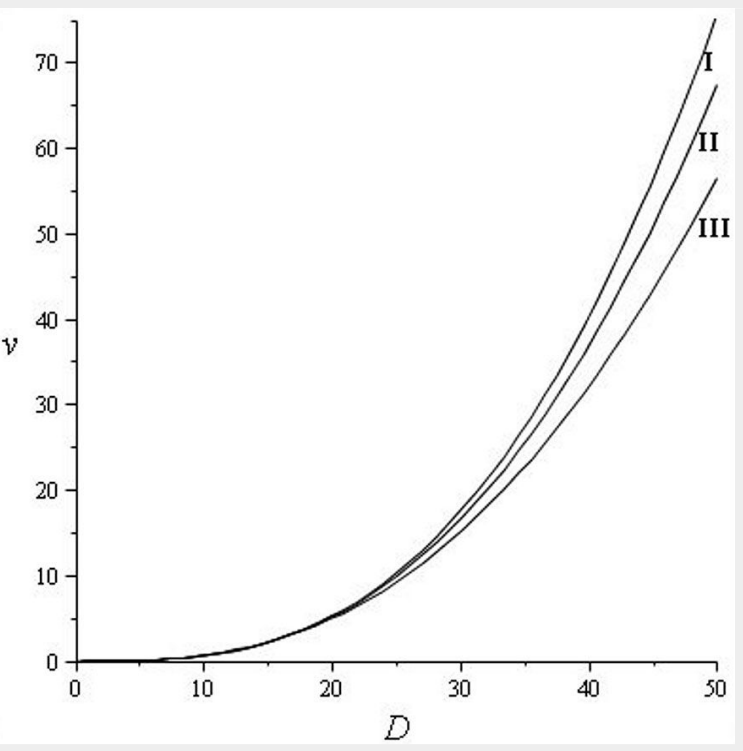

Tab. 3 - Numerical values of $s$ and $\hat{s}$ (as defined in eqn. 4) for Qualities I, II and III.

\begin{tabular}{|c|c|c|c|c|c|}
\hline Quality & $\begin{array}{c}G \\
\left(m^{2} \mathrm{ha}^{-1}\right)\end{array}$ & Variable & $\begin{array}{c}R=200 \\
\text { stem ha }^{-1}\end{array}$ & $\begin{array}{c}R=520 \\
\text { stem ha }^{-1}\end{array}$ & $\begin{array}{c}R=840 \\
\text { stem ha-1 }\end{array}$ \\
\hline \multirow{6}{*}{ Q I } & \multirow{2}{*}{22} & $s$ & 0.233770 & 0.323259 & 0.372742 \\
\hline & & $\hat{s}$ & 0.350669 & 0.375210 & 0.387782 \\
\hline & \multirow{2}{*}{24} & $s$ & 0.226305 & 0.314580 & 0.363570 \\
\hline & & $\hat{s}$ & 0.348471 & 0.372946 & 0.385489 \\
\hline & \multirow{2}{*}{26} & $s$ & 0.219546 & 0.306683 & 0.355205 \\
\hline & & $\hat{s}$ & 0.346454 & 0.370868 & 0.383384 \\
\hline \multirow{6}{*}{ Q II } & \multirow{2}{*}{22} & $s$ & 0.207665 & 0.292049 & 0.339704 \\
\hline & & $\hat{s}$ & 0.318779 & 0.345258 & 0.358932 \\
\hline & \multirow[b]{2}{*}{24} & $s$ & 0.200729 & 0.283764 & 0.330816 \\
\hline & & $\hat{s}$ & 0.316422 & 0.342804 & 0.356433 \\
\hline & \multirow{2}{*}{26} & $s$ & 0.194462 & 0.276245 & 0.322732 \\
\hline & & $\hat{s}$ & 0.314262 & 0.340553 & 0.354142 \\
\hline \multirow{6}{*}{ Q III } & \multirow{2}{*}{22} & $s$ & 0.180733 & 0.259707 & 0.305332 \\
\hline & & $\hat{s}$ & 0.278309 & 0.306537 & 0.321290 \\
\hline & \multirow{2}{*}{24} & $s$ & 0.174348 & 0.251850 & 0.296767 \\
\hline & & $\hat{s}$ & 0.275820 & 0.303901 & 0.318585 \\
\hline & \multirow{2}{*}{26} & $s$ & 0.168593 & 0.244738 & 0.288999 \\
\hline & & $\hat{s}$ & 0.273542 & 0.301487 & 0.316108 \\
\hline
\end{tabular}

The last row in Tab. 2 shows the average centage of wood of each diameter class price per cubic metre for trees belonging to the different diameter classes. This price was obtained by adding up the four rows above in Tab. 2 that show the contributions to the final value of a tree for the four industrial destinations according to the pergoing into each product type. The prices of particle board, poles, sawlogs, and highquality sawlogs were 6.0, 39.5, 19.6 and $33.2 € \mathrm{~m}^{-3}$, respectively. It is necessary to point out that the demand for timber poles in Spain is very high, and therefore they reach a higher price than larger-sized sawlogs.

\section{Results}

By substituting transition probabilities $p_{\mathrm{i}}$, recruitment $R$, basal area $G$, together with $w$ and $n$ into the eqn. 3 , we obtained $\hat{s}$, as summarised in Tab. 3, for selected scenarios.

On the other hand, by applying eqn. 7 and eqn. 8 , we obtained the components $N_{k}$ of the stable diameter distributions $W_{0}$ of the stand, as summarized in Tab. 4 for some scenarios. The $\lambda_{0}$ values were obtained for each scenario under conditions of stable equilibrium from eqn. 5 , using the transition matrix without harvests, and the $s$ values came from eqn. 1.

On the basis of the above data, by substituting $N_{k}, s, \hat{s}, i, T$ and $v_{k}$ into eqn. 13 to eqn. 16 , we obtained NPV, PV, $\rho_{\mathrm{NPV}}$ and $\rho_{\mathrm{PV}}$, as summarised in Tab. 5 and Tab. 6 , for $i=3 \%$, $T=90$ years and several scenarios. Additionally, Fig. 3 and Fig. 4 depict the points $(\hat{s}, N P V)$ for $T=90,(\hat{s}, P V),\left(\hat{s}, \rho_{\mathrm{NPV}}\right)$ for $T=$ 90 , and $\left(\hat{s}, \rho_{\mathrm{PV}}\right)$, respectively (198 points for each case).

The discount rates applied fell between $2 \%$ and $4 \%$, as is typical in forest management studies, and the time horizon used to calculate the NPV ranged between 50 and 130 years. The influence of small variations in the discount rate $i$, or the time horizon $T$, on the results was minimal because they did not change the behaviour of the expressions shown in Materials and Methods (chapter "NPV functions").

Regarding the regressions, we obtained the following results:

- As already mentioned, for previously defined values of $i$ and $T$, the dimensionless numbers $\rho_{\mathrm{NPV}}$ and $\hat{s}$ have a strong positive linear correlation (see Fig. 4). For $i=3 \%$, in particular, the total proportion of variance in $\rho_{\mathrm{NPV}}$ explained by $\hat{s}$ was $r^{2}=$ 0.99974 for Quality I, $r^{2}=0.99965$ for Quality II, and $r^{2}=0.99956$ for Quality III. It is important to note that such $r^{2}$ values do not depend on the planning horizon $T$. - Similarly, for each discount rate $i$, the dimensionless numbers $\rho_{\mathrm{PV}}$ and $\hat{s}$ have a strong positive linear correlation, with the same $r^{2}$ values as described above (Fig. 4).

Tab. 4 - Stable diameter distributions $\left(W_{0}\right)$. Components in stem ha', as defined in eqn. 7 and eqn. 8.

\begin{tabular}{ccll}
\hline Quality & $\begin{array}{c}\mathrm{G} \\
\left(\mathrm{m}^{2} \mathrm{ha}^{-1}\right)\end{array}$ & $R=200$ stem ha $^{-1}$ & $R=840$ stem ha-1 \\
\hline \multirow{3}{*}{ Q I } & 22 & {$[186.1,122.9,96.4,77.2,61.4,47.5,34.6,22.1,7.2]$} & {$[615.9,325.9,202.3,125.4,74.6,41.1,19.8,7.4,1.2]$} \\
& 24 & {$[188.3,125.7,99.8,81.0,65.4,51.4,38.3,25.3,8.6]$} & {$[626.4,336.8,212.6,134.2,81.5,45.9,22.7,8.8,1.5]$} \\
& 26 & {$[190.3,128.3,102.9,84.5,69.1,55.3,42.0,28.5,10.1]$} & {$[636.1,347.0,222.4,142.6,88.2,50.8,25.7,10.2,1.9]$} \\
\multirow{2}{*}{ Q II } & 22 & {$[233.3,147.0,113.7,90.3,71.1,53.9,37.2,16.6]$} & {$[757.0,376.4,226.4,135.8,77.3,39.6,16.4,3.7]$} \\
& 24 & {$[236.3,150.7,118.0,95.0,76.1,58.9,41.9,19.5]$} & {$[771.0,389.9,238.8,146.1,85.0,44.7,19.1,4.5]$} \\
& 26 & {$[239.1,154.0,122.0,99.5,80.9,63.8,46.6,22.6]$} & {$[783.9,402.5,250.5,156.0,92.7,49.8,22.0,5.4]$} \\
\multirow{2}{*}{ Q III } & 22 & {$[295.4,179.0,138.1,110.0,86.7,64.6,32.8]$} & {$[937.6,440.2,257.8,149.7,80.5,36.1,9.2]$} \\
& 24 & {$[299.6,183.8,143.8,116.4,93.7,71.8,38.0]$} & {$[956.3,457.2,273.0,162.1,89.4,41.4,11.0]$} \\
& 26 & {$[303.4,188.3,149.1,122.5,100.4,79.0,43.6]$} & {$[973.6,473.1,287.6,174.1,98.3,46.9,12.9]$} \\
\hline
\end{tabular}


Tab. 5 - NPV (for $T=90$ years) and PV values $\left(€\right.$ ha $\left.^{-1}\right)$ for the "sustainable/stable" harvesting strategies for $\mathrm{i}=3 \%$ and Qualities I, II and III.

\begin{tabular}{|c|c|c|c|c|c|}
\hline Quality & $G\left(m^{2} h a^{-1}\right)$ & Param & $R=200$ stem ha $^{-1}$ & $R=520$ stem ha $^{-1}$ & $R=840$ stem ha $^{-1}$ \\
\hline \multirow{6}{*}{ Q I } & \multirow{2}{*}{22} & NPV & 5319.159 & 6191.831 & 6500.993 \\
\hline & & PV & 5284.168 & 6283.379 & 6646.680 \\
\hline & \multirow{2}{*}{24} & NPV & 5701.675 & 6682.311 & 7038.929 \\
\hline & & PV & 5649.995 & 6770.617 & 7187.771 \\
\hline & \multirow{2}{*}{26} & NPV & 6074.394 & 7163.932 & 7569.088 \\
\hline & & PV & 6004.851 & 7247.846 & 7720.004 \\
\hline \multirow{6}{*}{ Q II } & \multirow{2}{*}{22} & NPV & 4185.287 & 5021.953 & 5359.973 \\
\hline & & PV & 4118.386 & 5065.793 & 5454.054 \\
\hline & \multirow{2}{*}{24} & NPV & 4474.700 & 5404.061 & 5785.948 \\
\hline & & PV & 4390.309 & 5441.416 & 5879.039 \\
\hline & \multirow{2}{*}{26} & NPV & 4756.044 & 5778.243 & 6204.543 \\
\hline & & PV & 4653.231 & 5808.146 & 6295.701 \\
\hline \multirow{6}{*}{ Q III } & \multirow{2}{*}{22} & NPV & 3131.227 & 3909.704 & 4264.179 \\
\hline & & PV & 3042.728 & 3913.709 & 4313.000 \\
\hline & \multirow{2}{*}{24} & NPV & 3336.493 & 4191.150 & 4584.694 \\
\hline & & PV & 3230.809 & 4186.435 & 4629.266 \\
\hline & \multirow{2}{*}{26} & NPV & 3535.449 & 4465.779 & 4898.460 \\
\hline & & PV & 3411.887 & 4451.574 & 4938.000 \\
\hline
\end{tabular}

Tab. 6 - $\rho_{\mathrm{NPV}}$ (for $T=90$ years) and $\rho_{\mathrm{PV}}$ dimensionless numbers for the "sustainable/stable" harvesting strategies for $i=3 \%$ and Qualities I, II and III.

\begin{tabular}{|c|c|c|c|c|c|}
\hline Quality & $G\left(m^{2} h a^{-1}\right)$ & Param & $R=200$ stem ha $^{-1}$ & $R=520$ stem ha $^{-1}$ & $R=840$ stem ha $^{-1}$ \\
\hline \multirow{6}{*}{ Q I } & \multirow{2}{*}{22} & $\rho_{\mathrm{NPV}}$ & 0.9195 & 1.2448 & 1.4246 \\
\hline & & $\rho_{\mathrm{PV}}$ & 0.9135 & 1.2632 & 1.4566 \\
\hline & \multirow{2}{*}{24} & $\rho_{\mathrm{NPV}}$ & 0.8924 & 1.2132 & 1.3913 \\
\hline & & $\rho_{\mathrm{PV}}$ & 0.8843 & 1.2293 & 1.4207 \\
\hline & \multirow{2}{*}{26} & $\rho_{\mathrm{NPV}}$ & 0.8679 & 1.1845 & 1.3609 \\
\hline & & $\rho_{\mathrm{pv}}$ & 0.8579 & 1.1984 & 1.3880 \\
\hline \multirow{6}{*}{ Q II } & \multirow{2}{*}{22} & $\rho_{\mathrm{NPV}}$ & 0.8247 & 1.1314 & 1.3046 \\
\hline & & $\rho_{\mathrm{PV}}$ & 0.8115 & 1.1412 & 1.3275 \\
\hline & \multirow{2}{*}{24} & $\rho_{\mathrm{NPV}}$ & 0.7995 & 1.1012 & 1.2723 \\
\hline & & $\rho_{\mathrm{PV}}$ & 0.7844 & 1.1089 & 1.2927 \\
\hline & \multirow{2}{*}{26} & $\rho_{\mathrm{NPV}}$ & 0.7767 & 1.0739 & 1.2429 \\
\hline & & $\rho_{\mathrm{PV}}$ & 0.7599 & 1.0795 & 1.2611 \\
\hline \multirow{6}{*}{ Q III } & \multirow{2}{*}{22} & $\rho_{\mathrm{NPV}}$ & 0.7268 & 1.0138 & 1.1796 \\
\hline & & $\rho_{\mathrm{PV}}$ & 0.7062 & 1.0149 & 1.1931 \\
\hline & \multirow{2}{*}{24} & $\rho_{\mathrm{NPV}}$ & 0.7036 & 0.9853 & 1.1485 \\
\hline & & $\rho_{\mathrm{PV}}$ & 0.6813 & 0.9841 & 1.1597 \\
\hline & \multirow{2}{*}{26} & $\rho_{\mathrm{NPV}}$ & 0.6827 & 0.9594 & 1.1203 \\
\hline & & $\rho_{\mathrm{PV}}$ & 0.6588 & 0.9564 & 1.1293 \\
\hline
\end{tabular}

Fig. 3 - First row: set of points ( $\hat{s}$, NPV) for $T=90$; second row: set of points ( $\hat{s}, P V)$. Left: Quality I; middle: Quality II; right: Quality III (198 total points for each case, 33 points for each basal area level, six points for each recruitment level, and $i=3 \%)$.
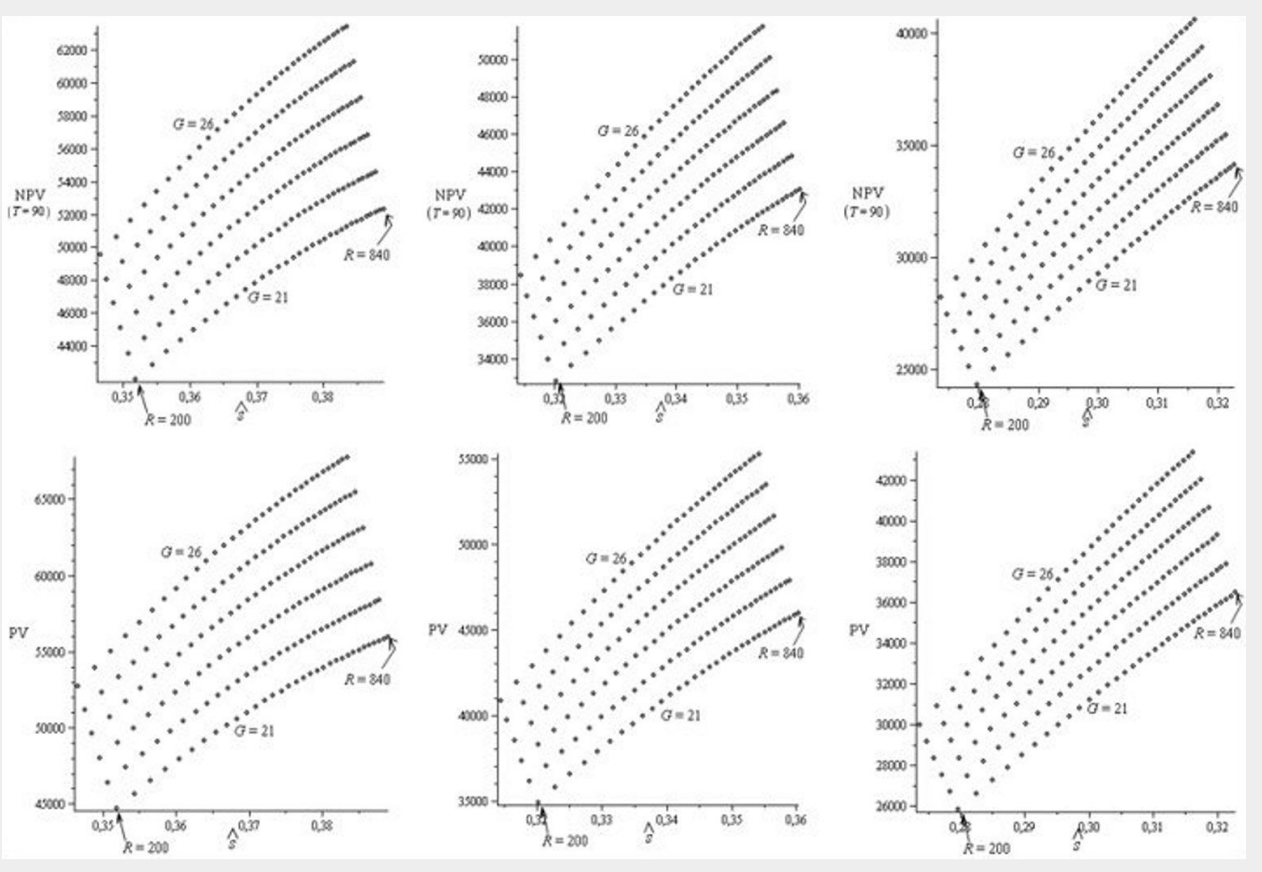

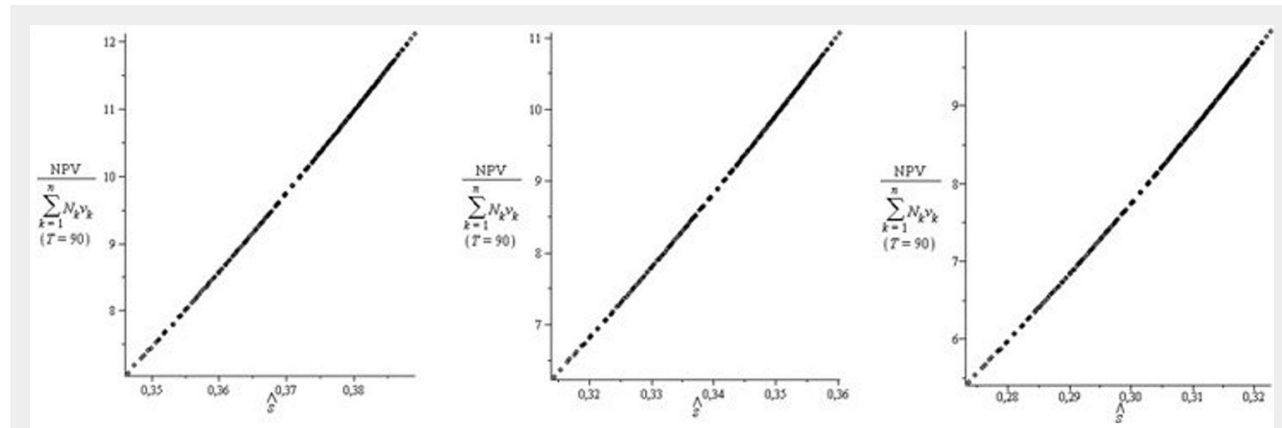

Fig. 4 - First row: set of points ( $\hat{s}$, $\left.\rho_{\mathrm{NPV}}\right)$ for $T=90$; second row: set of points $\left(\hat{s}, \rho_{\text {PV }}\right)$. Left: Quality I; middle: Quality II; right: Quality III (198 points for each case, and $i=3 \%$ ).
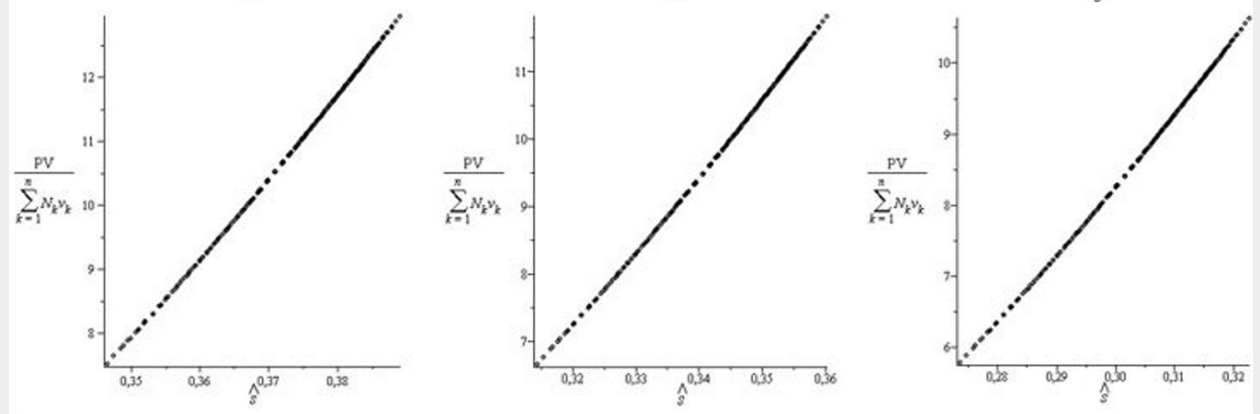

- For previously defined values of basal area (between $G=21 \mathrm{~m}^{2}$ ha ${ }^{-1}$ and $G=26 \mathrm{~m}^{2}$ $h^{-1}$ ), $i$ and $T$, the variables NPV and $\hat{s}$ have a strong positive linear correlation (Fig. 3). The same result holds for the variables $\mathrm{PV}$ and $\hat{s}$. The best approximations always occurred for the lowest level of diameter growth and the highest basal area scenarios, with $r^{2}$ being very close to 1 in all cases.

- For previously defined values of recruitment level (between $R=200$ and $R=840$ stems ha- ${ }^{-1}$, $i$ and $T$, the variables NPV and $\hat{s}$ have a strong negative linear correlation (Fig. 3). The same result holds for the variables PV and $\hat{s}$. The best approximations always occurred for the lowest level of diameter growth and the lowest recruitment scenarios, with $r^{2}$ being very close to 1 in all cases.

\section{Discussion and conclusions}

This paper proposes a simple and direct method based on dimensionless numbers, obtained under conditions of stable equilibrium from a matrix model, to provide reliable approximations of the NPV, PV, $\rho_{\mathrm{NPV}}$ and $\rho_{\mathrm{PV}}$ of a monospecific uneven-aged stand. In fact, these variables were related to $\hat{s}$ (see eqn. 3), which is a dimensionless number based on the following variables: (a) the transition probabilities $p_{k}$, which can be calculated from counts of observed transitions between adjacent diameter classes from $t$ to $t+1$; (b) the basal area of the stand $G$, and the global amount of recruitment $R$. Although Pinus nigra regenerates well in the study area under its own canopy (Retana et al. 2002, Tiscar 2007), there is a critical basal area that allows sufficient light transmittance for regeneration. This maximum value is around 20-30 $\mathrm{m}^{2}$ ha $^{-1}$ (Schütz 1989, Serrada et al. 1994, Monge Reyes 1997). On the other hand, basal area clearly below $20 \mathrm{~m}^{2} \mathrm{ha}^{-1}$ (before harvesting) could compromise natural re- generation (Serrada et al. 1994). Consequently, in addition to three levels of diameter growth (Qualities I-III), we considered six levels of stand basal area from $G=21$ to $G=26 \mathrm{~m}^{2} \mathrm{ha}^{-1}$, and 33 levels of global recruitment, from $R=200$ stems ha $^{-1}$ (scarce recruitment) to $R=840$ stems ha $^{-1}$ (abundant recruitment), creating a total of 594 planning scenarios. The corresponding problems simulated a wide variety of typical management cases in the study area; and (c) the number $n$ and width $w$ of the diameter classes. As shown in López \& Fullana (2015), these scaling factors $n$ and $w$ could have a limited influence on $\hat{s}$ and therefore on the NPV, PV, $\rho_{\mathrm{NPV}}$ and $\rho_{\mathrm{PV}}$ values.

The $\rho_{\mathrm{NPV}}$ and $\rho_{\mathrm{PV}}$ dimensionless numbers should not be interpreted as a kind of IRR, but as economic performance indicators for forest management inspired by the ROA accounting concept, using the NPV or PV derived from the sale of timber throughout a harvest cycle, plus the final stocking value (as numerator), and the fair value of standing timber (as denominator), showing how profitable the forest is relative to its total value, with sustainability and stability criteria. Application of the NPV (or PV) implies the introduction of a discount rate exogenously defined. In this regard, we applied the same criteria as in the International Financial Reporting Standards (IFRS), in particular IAS 41 (IASB 2000), to estimate that exogenous discount rate. In fact, IAS 41 (IASB 2000), in applying the expectation value approach to forest valuation, when referring to the process of deriving the present value of expected net cash flows for a forest stand, prescribed the use of a determined discount rate in each case, recommending that assumptions about these rates should be internally consistent with the underlying economic factors of the sector. By using a discount rate in accordance with interna- tional accounting standards, the possibility of manipulation should be avoided or limited. Thus, to consider the incorporation of eventual risks, in this study we initially chose a wide range of discount rates from $2 \%$ to $4 \%$, typical of forest management scenarios (Hyytiäinen \& Penttinen 2008, HMTreasury 2013, Knoke 2017). Note that (eqn. 17):

$$
\lim _{T \rightarrow+\infty} \rho_{N P V}=\rho_{P V}
$$

It is not surprising therefore that the highest $\rho_{\mathrm{NPV}}$ and $\rho_{\mathrm{PV}}$ values were obtained for Quality I, followed by Quality II and Quality III (see Tab. 6 and Fig. 4). In fact, since there is a strong positive linear correlation between these numbers and $\hat{s}$, and considering that the core of this dimensionless number $\hat{s}$ is given by the quotient (eqn. 18):

$$
\frac{R \prod_{i=1}^{n-1} p_{i}}{G}
$$

under the same conditions for $R$ and $G$, the faster the flow of the stems through the diameter classes (i.e., the higher product of the transition probabilities), the greater $\hat{s}$ and consequently the greater the $\rho_{\mathrm{NPV}}$ and $\rho_{P V}$ values. Likewise, within each site quality (where the product of the transition probabilities may be assumed to be constant), the key factor underlying the $\rho_{\mathrm{NPV}}$ and $\rho_{\mathrm{PV}}$ equations is the quotient $R / G$, which means that the greater $R / G$, the more profitable the forest will be (i.e., the $G=21 \mathrm{~m}^{2} \mathrm{ha}^{-1}$ with $R=840$ stems $^{-1}$ is the most favourable scenario in this context). Two arrows in Fig. 4 point in the directions of the higher and lower $R / G$ values.

Furthermore, the strong positive linear correlation between $\rho_{\mathrm{NPV}}$ and $\rho_{\mathrm{PV}}$ and $\hat{s}$ means that, stratifying the forest into uniform areas based upon tree diameter growths, the same linear regression line 
can be used in each stratum to estimate the $\rho_{\mathrm{NPV}}$ and $\rho_{\mathrm{PV}}$ dimensionless numbers. The same result holds for the variables NPV or PV and $\hat{s}$ for each basal area or recruitment levels, although, in the latter case, the corresponding strong linear correlation is negative.

Since the model rests on sustainability and stability criteria, it is important to investigate the sensitivity of the results to deviations from the equilibrium (stable diameter distribution); in particular, whether the strong linear relationship between the dimensionless numbers, $\rho_{\mathrm{NPV}}$ and $\rho_{\mathrm{PV}}$, and $\hat{s}$ is sensitive to changes in the equilibrium position. In this regard, there have been two recent studies involving Pinus nigra stands in the study area (López et al. 2013, 2016), both maximising the same NPV function, constrained by the same matrix model to describe the population dynamics, and with the same initial condition (the stable diameter distribution), as used in this study. Additionally, in the second one the final condition was assumed as the stable diameter distribution of the stand, and a wide variety of typical management scenarios in the study area, obtained by combining three rates of diameter growth (Qualities I-III), three levels of basal area ( $G$ $=22,24$ and $\left.26 \mathrm{~m}^{2} \mathrm{ha}^{-1}\right)$, and three levels of recruitment $(R=200,520$ and 840 stems $\mathrm{ha}^{-1}$ ), were considered. The first one (hereafter S1) showed that the economically optimal harvesting strategies underlying the solutions for that model changed the stand towards distributions substantially deviated from the stable diameter distribution; and the second (hereafter S2) revealed that the stand diameter distribution did not deviate substantially from the equilibrium position over time. The NPV values obtained for the optimal harvesting strategies from S2 were always below those of the optimal harvesting strategies from $\mathrm{S} 1$ (where no restrictions were introduced for the final state), and above the NPV values obtained under sustainability and stability criteria.

In each case, the $\rho_{\mathrm{NPV}}$ and $\rho_{\mathrm{PV}}$ dimensionless numbers were computed, and a regression analysis was conducted, using the same $\hat{s}$ values as in this study. The results showed that, in both S1 and S2 strategies the strong linear relationship between the dimensionless numbers $\rho_{\mathrm{NPV}}$ and $\rho_{\mathrm{PV}}$, and $\hat{s}$ was not sensitive to changes in the equilibrium position, with $r^{2}$ values being very close to 1 in all cases. The lowest $r^{2}$ values always occurred for the lowest level of diameter growth, with the minimum value of $r^{2}$ being 0.9986 for the strategy S1.

In conclusion, this study showed that, under sustainability and stability criteria, there is a strong influence of the dimensionless number $\hat{s}$ on the NPV and PV of the forest harvesting strategies. Additionally, $\rho_{\mathrm{NPV}}$ and $\rho_{\mathrm{PV}}$ might be interpreted as economic performance indicators for forest management, inspired by the ROA accounting concept, showing how profitable the forest is relative to its total value, with sustainability and stability criteria. Those dimensionless numbers would also allow the extraction of conclusions about the behaviour of NPV of the forest harvesting, capturing information of all the global variables involved in the problem (e.g., recruitment, basal area and transition probabilities between diameter classes). Moreover, the study showed that there are strong linear correlations between the variables, $\mathrm{NPV}, \mathrm{PV}, \rho_{\mathrm{NPV}}, \rho_{\mathrm{PV}}$, and $\hat{s}$.

\section{Acknowledgments}

The authors appreciate the helpful comments offered by the reviewers. The authors received no funding for this work, and have declared that no competing interests exist.

\section{References}

Brealey RA, Myers SC, Allen F (2016). Principles of corporate finance $\left(12^{\text {th }}\right.$ edn). McGraw-Hill/Irwin, New York, USA, pp. 976.

Buongiorno J, Michie BR (1980). A matrix model of uneven-aged forest management. Forest Science 26 (4): 609-625. [online] URL: http:// academic.oup.com/forestscience/article-abstra ct/26/4/609/4656453

Caswell H (2001). Matrix population models: construction, analysis, and interpretation ( $2^{\text {nd }}$ edn). Sinauer Associates Inc., Sunderland, MA, USA, pp. 710.

Ficko A, Roessiger J, Bončina A (2018). Optimizing silviculture in mixed uneven-aged forests to increase the recruitment of browse-sensitive tree species without intervening in ungulate population. iForest - Biogeosciences and Forestry 11: 227-236. - doi: 10.3832/ifor2567-011

Fortini LB, Cropper WP, Zarin DJ (2015). Modeling the complex impacts of timber harvests to find optimal management regimes for Amazon tidal floodplain forests. PLOS ONE 10 (8): e0136740. - doi: 10.1371/journal.pone. 0136740 Gotelli NJ (2001). A primer of ecology ( $3^{\text {rd }}$ edn). Sinauer Associates, Sunderland, MA, USA, pp. 290.

Grande MA, García Abril AE (2005). Los Pinares de Pinus nigra Arn. en España: ecología, uso y gestión. [The forests of Pinus nigra Arn. in Spain: ecology, use and management]. Fundación Conde del Valle de Salazar (FUCOVASA), Madrid, Spain, 2005, pp. 699. [in Spanish]

HM-Treasury (2013). The green book: appraisal and evaluation in central government. HM Treasury, London, UK, pp. 132. [online] URL: http://www.gov.uk/government/publications/t he-green-book-appraisal-and-evaluation-incentral-governent

Hyytiäinen K, Penttinen MJ (2008). Applying portfolio optimisation to the harvesting decisions of non-industrial private forest owners. Forest Policy and Economics 10 (3): 151-160. doi: 10.1016/j.forpol.2007.07.002

IASB (2000). International accounting standard 41 (IAS 41 Agriculture, december 2000). International Accounting Standards Board (IASB), International Financial Reporting Standards Foundation, London, UK, pp. A1293-A1305.

Knoke T (2017). Economics of mixed forests. In: "Mixed-Species Forests: Ecology and Manage- ment" (Pretzsch H, Forrester DI, Bauhus J eds). Springer-Verlag $\mathrm{GmbH}$, Berlin, Germany, pp. 545-579. - doi: 10.1007/978-3-662-54553-9_11

Lefkovitch LP (1965). The study of population growth in organisms grouped by stages. Biometrics 21: 1-18. - doi: 10.2307/2528348

Leslie PH (1945). On the use of matrices in certain population mathematics. Biometrika 33: 183-212. - doi: 10.1093/biomet/33.3.183

Liang J, Picard N (2013). Matrix model of forest dynamics: an overview and outlook. Forest Science 59 (3): 359-378. - doi: 10.5849/forsci.11-123 López I, Fullana C (2015). Dimensionless numbers for the sustainable harvesting of a monospecific uneven-aged forest. Canadian Journal of Forest Research 45: 1535-1545. - doi: 10.1139/cjfr2015-0140

López I, Ortuño SF, García Robredo F, Fullana C (2012). Is De Liocourt's distribution stable? Forest Science 58 (1): 34-46. - doi: 10.5849/forsci. 10-015

López I, Ortuño SF, García Robredo F, Fullana C (2013). Are the economically optimal harvesting strategies of uneven-aged Pinus nigra stands always sustainable and stabilizing? Forests 4: 830-848. - doi: 10.3390/f4040830

López I, Ortuño S, García Robredo F, Fullana C (2016). Optimizing the management of unevenaged Pinus nigra stands between two stable positions. iforest - Biogeosciences and Forestry 9:599-607. - doi: 10.3832/ifor1298-008

MAGRAMA (2012). Boletín mensual de estadística 1994-2011 [Monthly Statistical Bulletin 19942011]. Technical General Secretary, Spanish Ministry of Agriculture, Food and Environment, Madrid, Spain, pp. 48. [in Spanish]

Mills WL, Hoover W (1982). Investment in forest land: aspects of risk and diversification. Land Economics 58 (1): 33-51. - doi: 10.2307/3146075

Monge Reyes A (1997). Selvicultura y regeneración de Pinus nigra en las sierras Béticas [Forestry and regeneration of Pinus nigra in the Baetic mountain-range]. Doctoral thesis, ETSI de Montes de la UPM, Madrid, Spain, pp. 511. [in Spanish]

Montero G, Rojo A, Alía R (1992). Determinación del turno de Pinus sylvestris $L$. en el Sistema Central [Determination of rotation age for $\mathrm{Pi}$ nus sylvestris L. in the Central System]. Revista Montes 29: 42-47. [in Spanish]

Retana J, Espelta JM, Habrouk A, Ordóñez JL, Solà-Morales F (2002). Regeneration patterns of three Mediterranean pines and forest changes after a large wildfire in north-eastern Spain. Ecoscience 9: 89-97. - doi: 10.1080/119568 60.2002.11682694

Schütz JP (1989). Le régime du Jardinage. [The gardening regime]. Chaire de sylviculture, ETH Zürich, Switzerland, pp. 110. [in French]

Serrada R, Domínguez Lerena S, Sánchez Resco MI, Ruiz Ortiz J (1994). El problema de la regeneración natural de Pinus nigra Arn. [The problem of natural regeneration of Pinus nigra Arn.]. Revista Montes 36: 52-57. [in Spanish]

Siegel W, Hoover W, Haney H, Liu K (1995). Forest owners' guide to the federal income tax. Agriculture Handbook No. 708, USDA Forest Service, Washington, DC, USA, pp. 138.

Szirtes T (2007). Applied dimensional analysis and modeling ( $\left(2^{\text {nd }}\right.$ edn). Elsevier ButterworthHeinemann, Burlington, MA, USA, pp. 856. 
Tiscar PA (2007). Dinámica de regeneración de Pinus nigra subs. salzmannii al sur de su área de distribución: etapas, procesos y factores implicados. [Regeneration dynamics of Pinus nigra subs. salzmannii at the southeast of its distribution area: stages, processes and factors involved]. Investigación Agraria: Sistemas y Recursos Forestales 16 (2): 124-135. [in Spanish] doi: $10.5424 / \mathrm{srf} / 2007162-01003$

Trasobares A, Pukkala T (2004). Optimising the management of uneven-aged Pinus sylvestris $L$. and Pinus nigra Arn. mixed stands in Catalonia, north-east Spain. Annals of Forest Science 61:
747-758. - doi: 10.1051/forest:2004071

Usher MB (1969). A matrix model for forest management. Biometrics 25 (2): 309-315. - doi: $10.2307 / 2528791$

Vanclay JK (2012). Modelling continuous cover forests. In: "Continuous Cover Forestry" (Pukkala T, Von Gadow K eds). Managing Forest Ecosystems, vol. 23, Springer, Dordrecht, Netherlands, pp. 229-241. - doi: 10.1007/978-94-0072202-6_7

Van Mantgem PJ, Stephenson NT (2005). The accuracy of matrix population model projections for coniferous trees in the Sierra Nevada, Cali- fornia. Journal of Ecology 93: 737-747. - doi: 10.1111/j.1365-2745.2005.01007.x

Weber MW (2002). Portefeuille- und real-options preist- theorie und forstliche entscheidungen [Portfolio and real option price- theory and forestry decisions]. Sauerländer's Verlag, Frankfurt, Germany, pp. 197. [in German]

Zhou M, Liang J, Buongiorno J (2008). Adaptive versus fixed policies for economic or ecological objectives in forest management. Forest Ecology and Management 254 (2): 178-187. - doi: 10.1016/j.foreco.2007.07.035 